\title{
The Conjugated Phenylene Polymer-Modified Photoanodes for Quantum Dot-Sensitized Solar Cells
}

\author{
So-Ra Lee, Da-Seul Kim, and Seong-Ho Choi \\ Department of Chemistry, Hannam University, Daejeon 34054, Republic of Korea \\ Correspondence should be addressed to Seong-Ho Choi; shchoi@hnu.kr
}

Received 20 October 2016; Accepted 23 November 2016; Published 9 January 2017

Academic Editor: Zheng Zhang

Copyright (C) 2017 So-Ra Lee et al. This is an open access article distributed under the Creative Commons Attribution License, which permits unrestricted use, distribution, and reproduction in any medium, provided the original work is properly cited.

\begin{abstract}
Five types of conjugated phenylene polymer-modified photoanodes for quantum dot-sensitized solar cells (QDSSCs) were prepared by immobilization of CdSe QDs after electrochemical polymerization of functionalized phenyldiazonium salts onto ITO glass electrodes. The successful preparation of the conjugated phenylene polymer-modified photoanodes for QDSSCs was confirmed by scanning electron microscopy (SEM), X-ray photoelectron spectroscopy (XPS), FT-IR spectroscopy, UV-visible spectroscopy, contact angles, and electrochemical impedance spectroscopy. The open-circuit voltage and fill factor in QDSSCs with the conjugated phenylene polymer with - $\mathrm{COOH}$ photoanodes were achieved at $0.52 \mathrm{~V}$ and $76.8 \%$, respectively, and the energy conversion efficiency was improved to $2.73 \%$ using the conjugated phenylene polymer with - $\mathrm{COOH}$ photoanodes.
\end{abstract}

\section{Introduction}

Quantum dot-sensitized solar cells (QDSSCs) have attracted considerable attention over the past few years as a promising candidate for the development of next generation solar cells because of the superior intrinsic properties of quantum dots (QDs), which include high molar extinction coefficients, easily tunable band gaps, large intrinsic dipole moments, and possible multiple carrier generation [1-3]. However, the power conversion efficiency of QDSSCs is not yet competitive with that of dye-sensitized solar cells (DSSCs). The poor performance of QDSSCs is mainly due to weak electron collection by the $\mathrm{TiO}_{2}$ from the QDs and charge recombination at the QD-electrolyte interface. Therefore, an effective way to improve the efficiency of QDSSCs would be to prevent back electron transfer or recombination processes and accelerate the transportation of separated charges to the contact electrode.

In order to increase the efficiency of QDSSCs, there is a need to search for novel electron transfer materials for their working electrodes. To improve the power conversion efficiency of QDSSCs, various structures have been employed to fabricate the photoanodes, such as metal complexes [4], conjugated polymer [5], mesoporous films, hierarchical spheres, nanoflowers [6], nanowires (NWs) [7-9], nanorods (NRs)
[10-13], and nanotube (NT) arrays [14-16]. Recently, many new strategies, especially surface and interface treatments, have been also employed to modify the conjugated polymer of the photoanodes with the aim of reducing recombination and improving the transport of photoexcited carriers at the interface. The introduction of a phenylene polymer on the electrode surface by radical polymerization [17-20] could provide an electron transfer mediator because the phenylene site has a conjugated bond, which means there are alternating double and single bonds, and it has a low band gap of about 2.9-3.9 eV. Among various conductive polymers, polythiophene is of great interest because of a simple preparatory process, ease of mass production, and low cost. Nevertheless, its relatively high charge transfer resistance is the main barrier toward its practical application.

In this work, we synthesized conjugated phenylene polymer-modified photoanodes by immobilization of Lcysteine-stabilized QDs after electrochemical polymerization of functionalized phenyldiazonium salts onto ITO glass electrodes. The prepared conjugated phenylene polymermodified photoanodes were characterized by FT-IR spectroscopy (FT-IR), X-ray photoelectron spectroscopy (XPS), scanning electron microscopy (SEM), contact angle, and electrochemical impedance in order to confirm whether or not the preparation was successful. Furthermore, the 
performance of solar cells assembled with the conjugated phenylene polymer-modified photoanodes was determined with a solar simulator.

\section{Experimental}

2.1. Materials. The 4-aminobenzoic acid, 4-aminothiophenol, sodium nitrite $\left(\mathrm{NaNO}_{2}\right)$, 3-thiopheneethanol, and Lcysteine (L-cys) were purchased from Sigma-Aldrich (USA), while 1,4-phenylenediamine and 4-aminophenol were purchased from Tokyo Chemical Industry Co., Ltd. (Japan). Cadmium chloride was obtained from Junsei Chemical Co., Ltd. (Japan). Selenium was supplied from Acros Organics (Belgium). Sodium borohydride was provided from Samchun Pure Chemical Co., Ltd. (Korea). All other chemicals were of analytical grade. Water was purified using a Millipore purification system (Millipore Co., Ltd., MA, USA).

2.2. Synthesis of L-Cysteine-Capped CdSe QDs. Synthesis of L-cys-capped CdSe QDs was carried out in aqueous solution by a chemical reduction method [21]. In detail, in a round flask $\mathrm{CdCl}_{2}$ (0.24 mmol, $0.048 \mathrm{~g}$ ) and L-cysteine $(0.24 \mathrm{mmol}$, $0.029 \mathrm{~g})$ were dissolved in distilled water $(80 \mathrm{~mL})$, and $0.1 \mathrm{M}$ $\mathrm{NaOH}$ solution was added until the L-cysteine was completely dissolved. This solution was stirred and kept at $100^{\circ} \mathrm{C}$. In another round flask, Se powder $(0.02 \mathrm{~g})$ and $\mathrm{NaBH}_{4}(0.10 \mathrm{~g})$ were dissolved in anhydrous ethanol $(15 \mathrm{~mL})$ under stirring and $\mathrm{N}_{2}$ gas. After this solution had been completely dissolved, $\mathrm{H}_{2} \mathrm{SO}_{4}(0.1 \mathrm{M}, 20 \mathrm{~mL})$ was dropped into the flask. $\mathrm{H}_{2} \mathrm{Se}$ gas was generated by the reaction of $\mathrm{H}_{2} \mathrm{SO}_{4}$ with $\mathrm{Se}$ and $\mathrm{NaBH}_{4}$ and carried to another flask via a glass tube, which was connected between the round reaction flasks. Finally, CdSe QDs could be synthesized by this reaction.

2.3. Preparation of CdSe QDs-Sensitized Solar Cells. The precursors for preparation of the conjugated phenylene polymer-modified photoanodes are shown in Figure 1. For synthesis of 4-carboxybenzenediazonium salt, $0.01 \mathrm{~mol}$ of 4aminobenzoic acid was dissolved in $20 \mathrm{~mL}$ of warm aqueous hydrochloride solution $(0.22 \mathrm{M})$. After cooling to $0^{\circ} \mathrm{C}$, $20 \mathrm{~mL}$ of aqueous $\mathrm{NaNO}_{2}(0.011 \mathrm{M})$ was added slowly to the reaction mixture with stirring. A solid powder of 4carboxybenzenediazonium salt was obtained by filtration, and then the synthesized 4-carboxyphenyldiazonium salt was stored at $4^{\circ} \mathrm{C}$ until using electrochemical polymerization onto an ITO glass electrode was performed in phosphate buffer solution ( $\mathrm{PBS}, \mathrm{pH}=7.0$ ) in the presence of the synthesized 4carboxyphenyldiazonium salt. Other conjugated phenylene polymer-modified ITO electrodes were also prepared by a similar method as that described above except that modification of the electrode was done by electrochemical polymerization of the $\underline{3}$ precursor in acetonitrile electrolyte containing tetrabutylammonium tetrafluoroborate. QDSSCs were assembled into a sandwich structure using a QD-anchored electrode as the working electrode, an ITO electrode as the counter electrode, and a $0.5 \mathrm{M} \mathrm{Na}_{2} \mathrm{~S}, 2 \mathrm{M} \mathrm{S}$, and $0.2 \mathrm{M} \mathrm{KCl}$ in water/methanol (3:7 in volume) mixed solution as the electrolyte.
2.4. Instruments. Cyclic voltammetry (CV) was performed using a VersaSTAT 3 potentiostat/galvanostat (Ametek PAR, USA) and a conventional three-electrode system comprising an ITO glass substrate (In-doped $\mathrm{SnO}_{2}$, resistance: $10 \Omega \mathrm{sq}^{-1}$, and thickness: $0.7 \mathrm{~mm}$ ) as the working electrode, a platinum wire as the counter electrode, and $\mathrm{Ag} / \mathrm{AgCl}$ (saturated $\mathrm{KCl}$ ) as the reference electrode. Electrochemical impedance spectroscopy (EIS) was performed using a PP240 and IM6ex (ZAHNER-elektrik GmbH \& Co. KG, Germany). EIS measurements were performed in the presence of PBS $(\mathrm{pH}=7.0)$ containing a $1.0 \mathrm{mM} \mathrm{K}_{3} \mathrm{Fe}(\mathrm{CN})_{6} / \mathrm{K}_{4} \mathrm{Fe}(\mathrm{CN})_{6}(1: 1)$ mixture as a redox probe in the frequency range between $100 \mathrm{mHz}$ and $10 \mathrm{kHz}$ at the amplitude of $+10 \mathrm{mV}$.

The morphology of the composites was observed using a field emission transmission electron microscope (FE-TEM, Tecnai G2 F30 S-Twin, FEI, USA) at $200 \mathrm{kV}$. The absorption spectrum of L-cys-capped CdSe QDs was obtained using a UV-VIS spectrometer (UV-3101PC, Shimadzu Corp., Japan). The photoluminescence (PL) measurement was carried out by a fluorescence spectrometer (FluoroMate FS-2, Scinco Co., Ltd., Korea). DLS analysis was performed using a DynaPro NanoStar (Wyatt Technology Corp., USA). FT-IR spectrum of the prepared photoanodes was obtained using a Nicolet iS10 (Thermo Fisher Scientific Inc., USA). Surface properties were characterized by a scanning electron microscopy (SEM, S-4800, Hitachi Co., Ltd., Japan), contact angle (Phoenix 300, Surface Electro Optics Co., Ltd., Korea), and X-ray photoelectron spectroscopy (MultiLab. ESCA 2000, Thermo Fisher Scientific Inc., USA).

Photovoltaic measurements of the QDSSCs were performed at an illumination of $100 \mathrm{~mW} \mathrm{~cm}^{-2}$ (AM $1.5 \mathrm{G}$ ) generating from a solar simulator (Polaronix K201/LAB50, McScience, Korea) equipped with a $200 \mathrm{~W}$ Xenon lamp. Current-voltage curves were obtained by applying an external bias to the cell and measuring the generated photocurrent with a photovoltaic power meter (Polaronix K101/LAB20, McScience, Korea).

\section{Results and Discussion}

3.1. Characterization of the L-Cysteine-Capped CdSe QDs. Quantum dots are widely used not only in the photoelectrochemical field but also in biosensors, biological imaging, and bioconjugates because of their remarkable electronic and optic properties. In order to apply photoelectrochemical fields, we synthesized L-cysteine-capped CdSe QDs using a chemical reduction method as in the following process.

$$
\begin{gathered}
\mathrm{NaBH}_{4}+\mathrm{Se}+3 \mathrm{C}_{2} \mathrm{H}_{5} \mathrm{OH} \longrightarrow \\
\mathrm{NaHSe}+\mathrm{B}\left(\mathrm{OC}_{2} \mathrm{H}_{5}\right)_{3}+3 \mathrm{H}_{2} \\
\mathrm{NaHSe}+\mathrm{H}_{2} \mathrm{SO}_{4} \longrightarrow \mathrm{H}_{2} \mathrm{Se}(\mathrm{g})+\mathrm{NaSO}_{4} \\
\mathrm{HOOCNH} \mathrm{C}_{2} \mathrm{H}_{3} \mathrm{SH}+\mathrm{NaOH}+\mathrm{CdCl}_{2} \longrightarrow \\
\mathrm{HOOCNH}_{2} \mathrm{C}_{2} \mathrm{H}_{3} \mathrm{~S}^{-} \mathrm{Cd}^{+} \\
\mathrm{H}_{2} \mathrm{Se}(\mathrm{g})+\mathrm{NaCl}+\mathrm{HOOCNH}_{2} \mathrm{C}_{2} \mathrm{H}_{3} \mathrm{~S}^{-} \mathrm{Cd}^{+} \longrightarrow \\
\mathrm{L}-\text { cys-capped CdSe }
\end{gathered}
$$




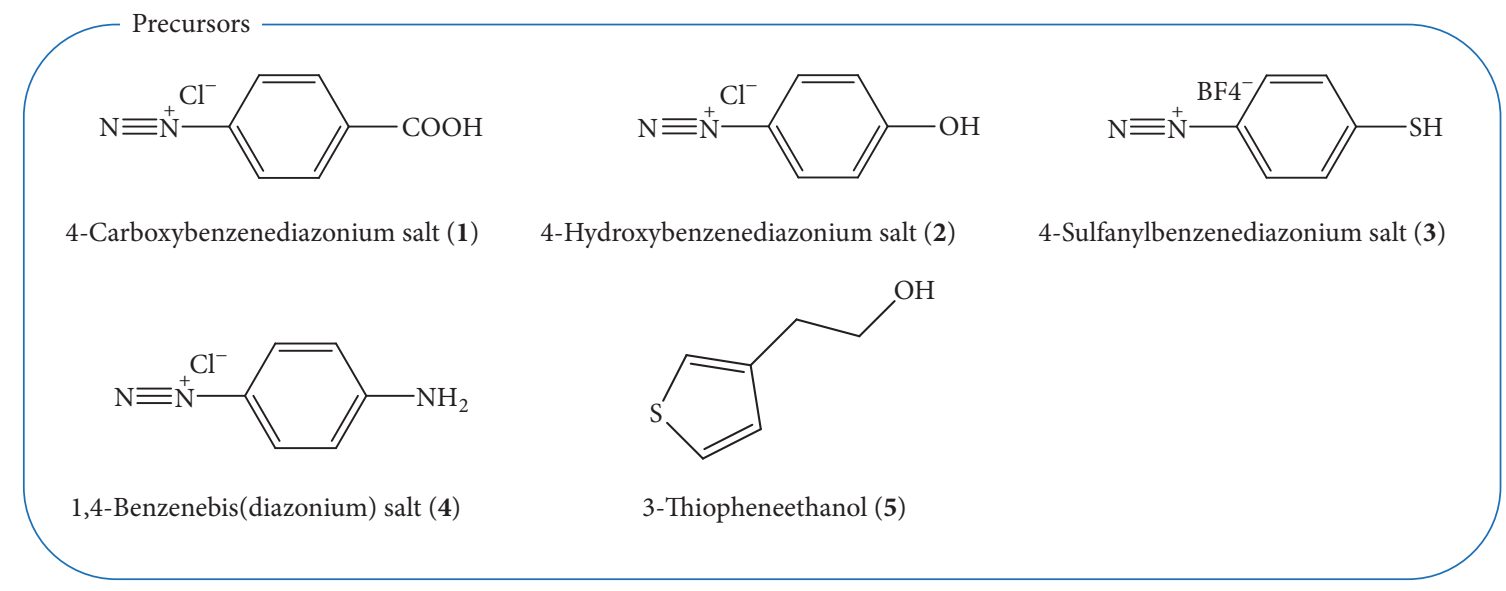

Figure 1: Precursors for preparation of the conjugated phenylene polymer-modified photoanodes.
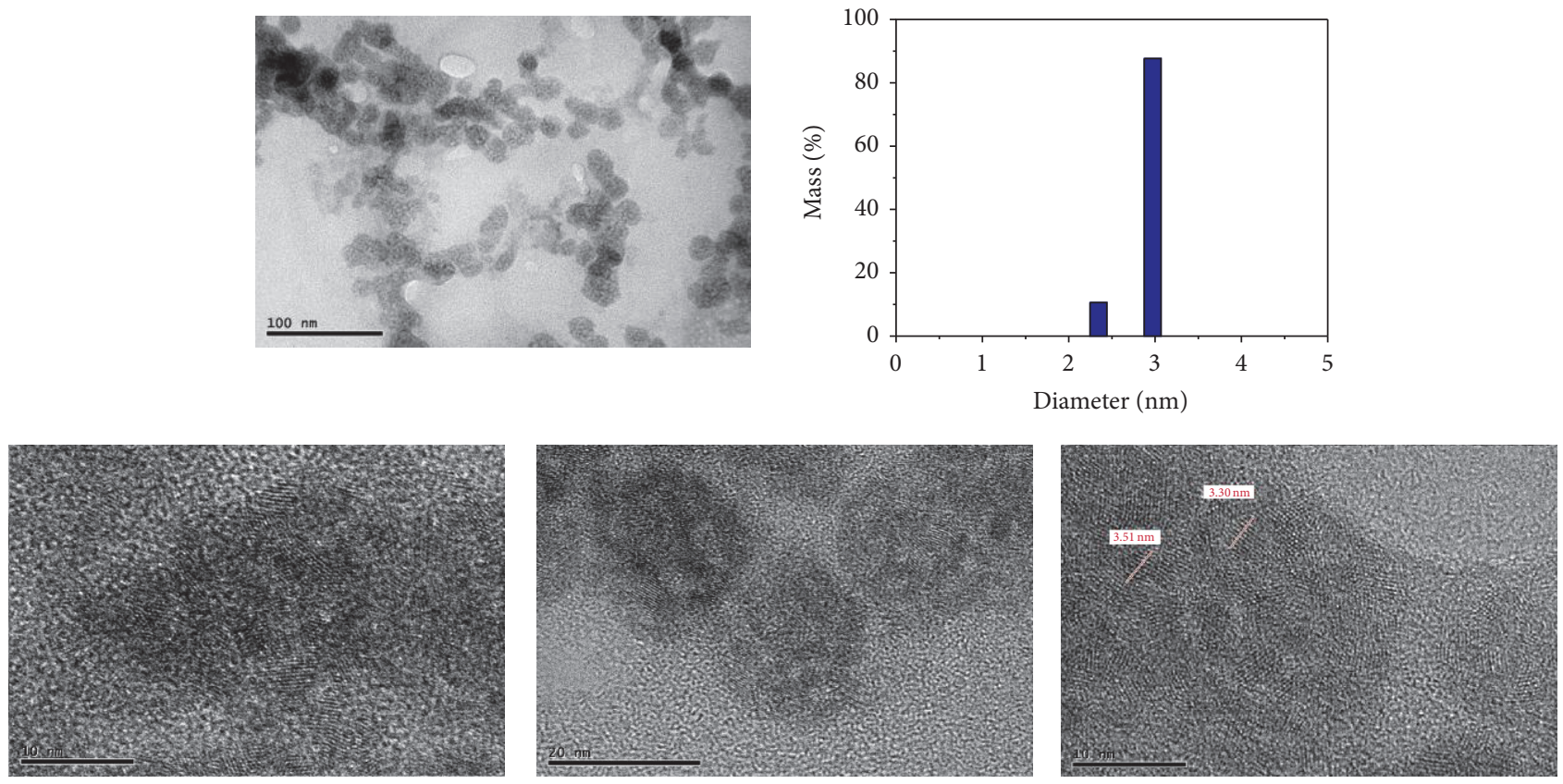

FIGURE 2: HR-TEM images and DLS data of the synthesized L-cys-stabilized CdSe QDs.

Morphology and particle size of the synthesized L-cyscapped CdSe QDs are shown in Figure 2. In general, the Lcys-capped CdSe QDs were spherical with an aggregation of small particles of $\sim 3 \mathrm{~nm}$. In the DLS data, it was observed that there was a distribution of L-cys-capped CdSe QDs of two sizes of 2.3 and $3 \mathrm{~nm}$ because of the aggregation of small QDs with each other, and the results show that the L-cys-capped CdSe QDs in aqueous solution were aggregated at room temperature. The UV-vis spectrum, photoluminescence (PL) spectrum, and DLS data of L-cys-capped CdSe QDs are also shown in Figure 3. The absorbance spectrum displays an excitation peak at $472 \mathrm{~nm}$. The luminescence spectrum at $581 \mathrm{~nm}$ is confirmed. The band gap and the size of the L-cyscapped CdSe QDs were calculated as $2.25 \mathrm{eV}$ and $10.7 \mathrm{~nm}$, respectively, via UV spectrum data in accordance with the following equation:

$$
\begin{aligned}
\text { Band gap }(\mathrm{eV})= & \frac{1240}{x}(2.24 \mathrm{eV}) \\
\operatorname{Size}(\mathrm{nm})= & \left(-6.6521 \times 10^{-8}\right) \lambda_{\mathrm{uv}}{ }^{3} \\
& +\left(1.9557 \times 10^{-4}\right) \lambda_{\mathrm{uv}}{ }^{2} \\
& -\left(9.2352 \times 10^{-2}\right) \lambda_{\mathrm{uv}} \\
& +13.29(10.8 \mathrm{~nm}) .
\end{aligned}
$$



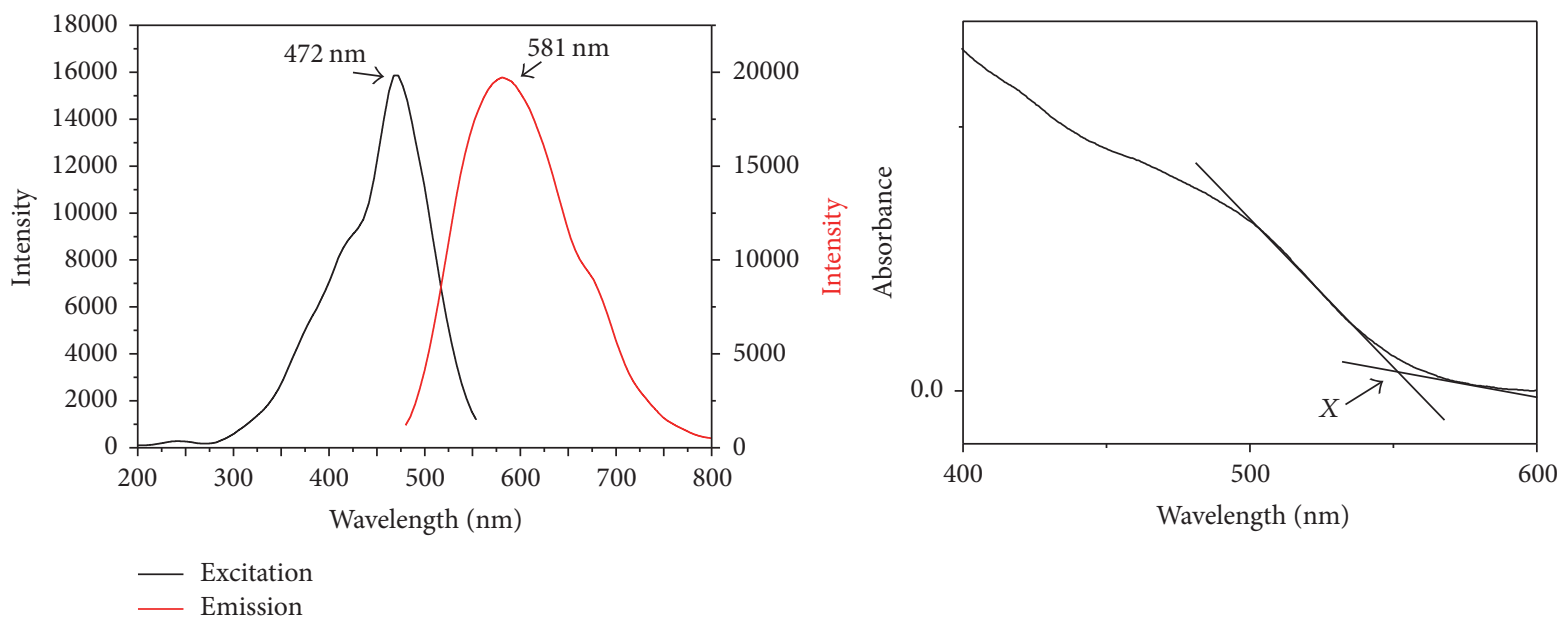

FIGURE 3: Photoluminescence and UV-vis spectrum of the synthesized L-cys-stabilized CdSe QDs.

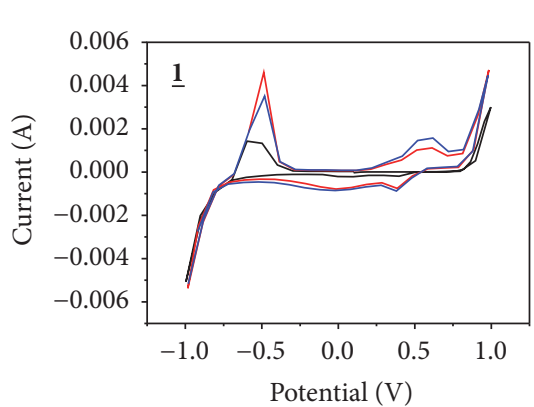

- 1st cycle — 10th cycle
5th cycle

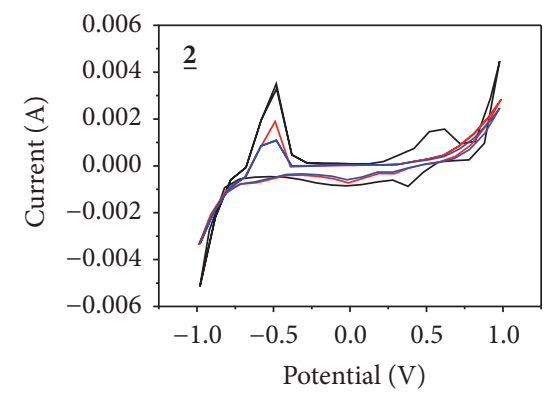

- 1st cycle — 10th cycle
5th cycle

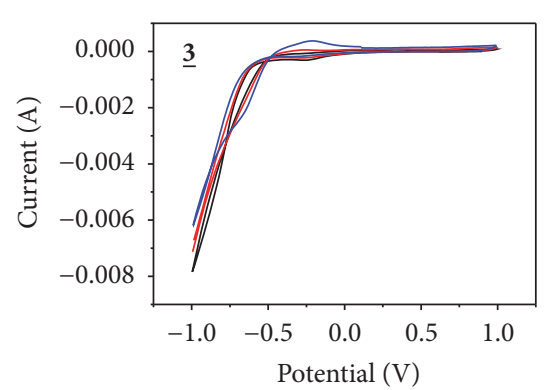

- 1st cycle - 10th cycle
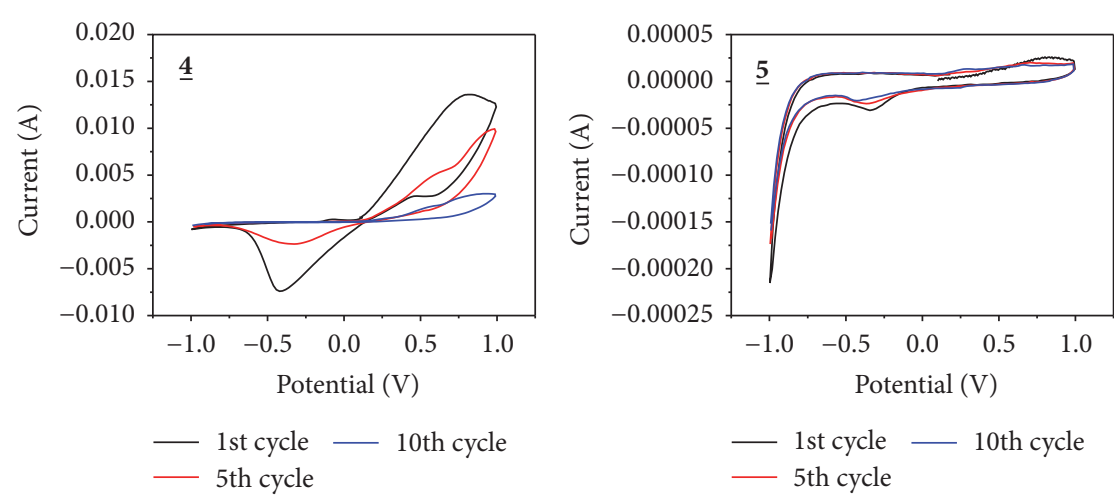

FIGURE 4: Cyclic voltammograms during electrochemical polymerization of precursors in PBS electrolyte with scan rate $100 \mathrm{mV} / \mathrm{s} . \underline{\mathbf{3}}$ was performed in $0.1 \mathrm{M}$ tetrabutylammonium tetrafluoroborate acetonitrile electrolyte.

3.2. Characterization of the Conjugated Phenylene PolymerModified Photoanodes. In order for electron transfer to be made easily onto the photoelectrode, the conjugated phenylene polymers were grafted onto the ITO glass surface by electrochemical polymerization in accordance with a similar method to that described previously [21]. Consecutive CVs (Figure 4) were obtained with a scan rate of $100 \mathrm{mV} / \mathrm{s}$ during electrochemical polymerization of the precursors in PBS electrolyte ( $\mathrm{pH}=7.0$ ), except for the CV of $\underline{\mathbf{3}}$, which was obtained by electrochemical polymerization of the $\underline{3}$ precursor in acetonitrile electrolyte with $0.1 \mathrm{M}$ tetrabutylammonium tetrafluoroborate because of insoluble properties in PBS buffer solution. In the $1 \mathrm{CV}$ of Figure 4, the oxidation peak observed at around $-0.50 \mathrm{~V}$ corresponds to a reduction of 4-carboxyphenyl diazonium salts to 4-carboxyphenyl radicals at the respective electrode on the 1st cycles (see, $\underline{1}$ in Figure 5). In the 5th cycles, the intensity of the $-0.50 \overline{\mathrm{V}}$ oxidation peak was increased because of the formation of many 4-carboxyphenyl radicals. In the 10th cycles, the characteristic oxidation peak observed at $0.57 \mathrm{~V}$ is because of 


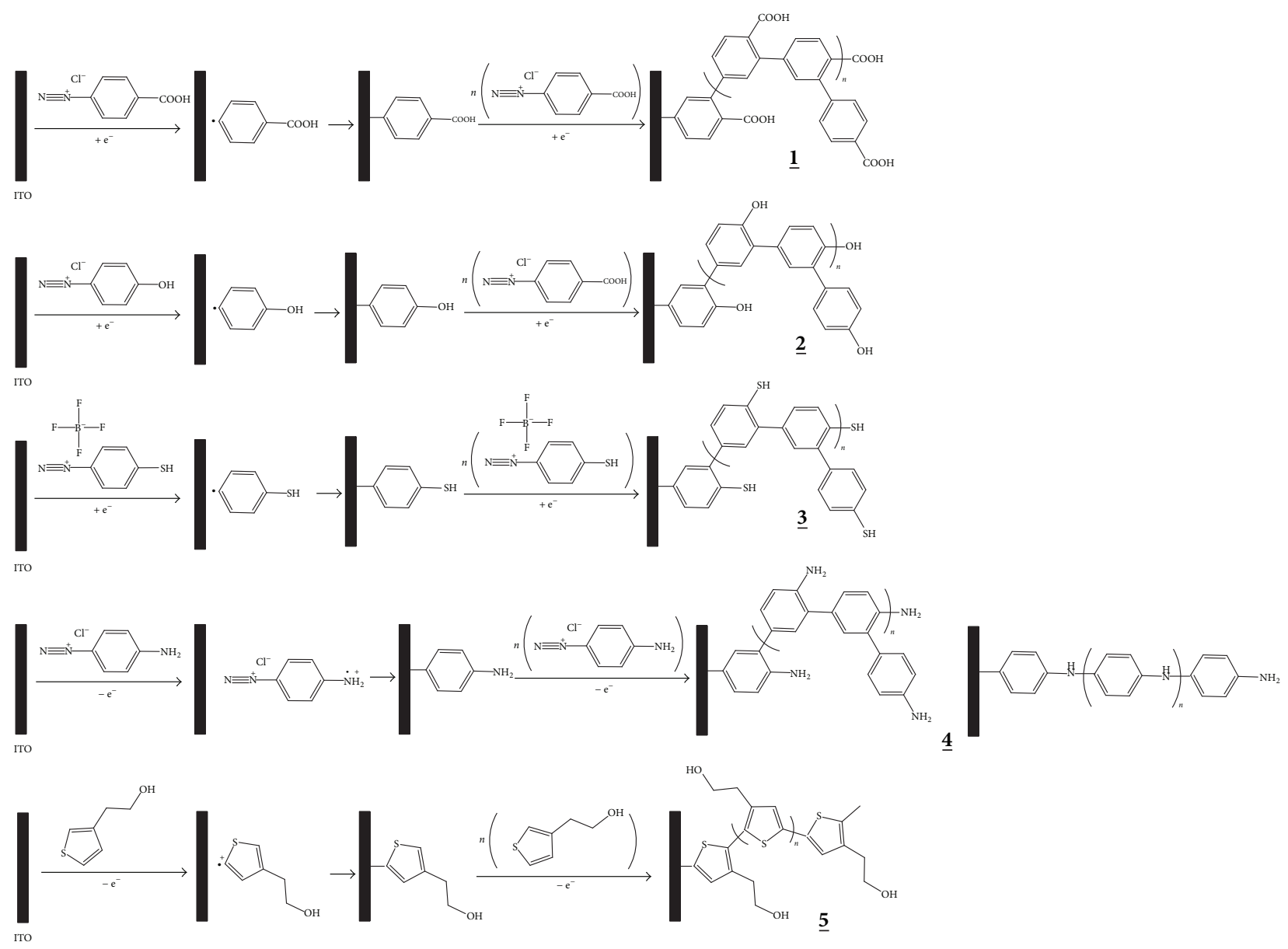

FIGURE 5: Electrochemical polymerization mechanism onto the surface of ITO electrode.

electrochemical polymerization (see structure $\underline{1}$ in Figure 5). Earlier reports suggested that electrochemical reduction of diazonium salts on ITO surfaces could result in the formation of thin film by heterogeneous one-electron reduction in aprotic solvents [12]. In the $2 \mathrm{CV}$ of Figure 4, the oxidation peaks exhibited at $-0.50 \mathrm{~V}$ appear in similar patterns to those in the $\underline{\mathbf{1}} \mathrm{CV}$ because of 4-hydroxyphenyl radicals $(\underline{\mathbf{2}} \mathrm{CV}$ in Figure 5). With increasing redox cycles, the oxidation peaks at $-0.50 \mathrm{~V}$ were increased because of the formation of hydroxyphenyl radicals, namely, electrochemical polymerization. The oxidation peaks with the acetonitrile electrolyte were displayed around $-0.25 \mathrm{~V}$ in the $\underline{\mathbf{3}} \mathrm{CV}$ of Figure 4 because of 4 - thiophenyl radicals (see 3 in Figure 5). On the other hand, the reduction peaks appeared around $-0.5 \mathrm{~V}$ on the $\mathrm{CV}$ of the 4 -aminophenyl diazonium chloride ( $\underline{4}$ in Figure 4) as shown in $\underline{4}$ in Figure 5. With increasing redox cycles, current values were decreased because the electron was not transferred onto the 4-aminophenyl polymer grafted ITO glass electrode, which indicates that the electrons were not transferred onto the grafted polymer-modified ITO glass electrode. From these results, the structure of the grafted polymers onto the surface of the ITO glass electrode is considered to be as shown in Figure 5- $\underline{4}$. With 3-thiopheneethanol ( $\underline{\mathbf{5}}$ of Figure 4), the first reduction peak was at $-0.5 \mathrm{~V}$, and the reduction peaks moved to $-0.25 \mathrm{~V}$ with increasing $\mathrm{CV}$ cycles while the current values were also increased. These results show that the conjugated phenylene polymers were successfully grafted onto the surface of the ITO glass electrode (Figure 5- $\underline{\mathbf{5}}$ ).

FT-IR spectra of the conjugated phenylene polymermodified ITO glass electrode prepared by electrochemical polymerization were obtained (Figure 6). In the 1 electrode, the characteristic peak at $1720 \mathrm{~cm}^{-1}$ corresponding to carboxylic acid and the $\mathrm{C}_{6} \mathrm{H}_{5}-\mathrm{C}$ vibration peak at $1200 \mathrm{~cm}^{-1}$ indicating the aromatic ring appear. In the $\underline{2}$ electrode, a broad peak at $3400 \mathrm{~cm}^{-1}$ attributed to the $\mathrm{O}-\mathrm{H}$ vibration was observed. The characteristic peak at $2950 \mathrm{~cm}^{-1}$ due to the-S$\mathrm{H}$ bond was detected in the $\underline{3}$ electrode. In the $\underline{4}$ electrode, a sharp peak around $3300 \mathrm{~cm}^{-1}$ due to the $\mathrm{N}-\mathrm{H}$ bond was observed. In the $\underline{\mathbf{5}}$ electrode, a broad peak at $3400 \mathrm{~cm}^{-1}$ attributed to the $\mathrm{O}-\mathrm{H}$ bond appeared. These results show that the conjugated phenylene polymer-modified ITO glass electrodes were successfully prepared by electrochemical polymerization.

The C 1s high-resolution XPS spectra of the conjugated phenylene polymer-modified ITO glass electrode prepared by electrochemical polymerization are shown in Figure 7. In the high-resolution XPS spectra of the 1 electrode, the $\mathrm{C}=\mathrm{O}$ group appears at $288 \mathrm{eV}$ and $\mathrm{C}-\mathrm{O}$ group appears at $286.5 \mathrm{eV}$ 


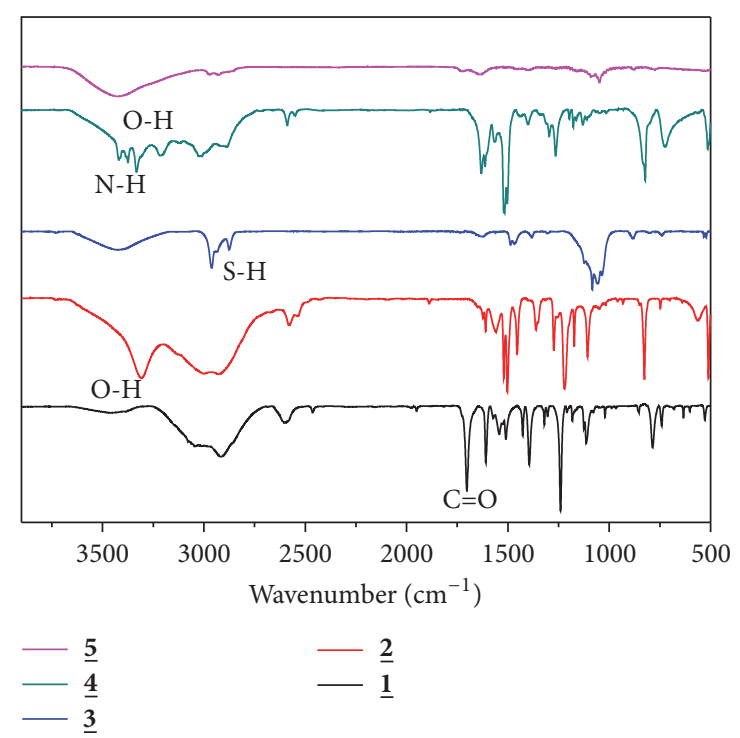

FIGURE 6: FT-IR spectra of the conjugated phenylene polymermodified ITO electrodes.

because of the carboxyl group. In the $\underline{\mathbf{2}}$ electrode, a small amount of the C-O group appears because of C-O-H. In the $\underline{3}$ electrode, a small C-S peak was observed because of the thiol group as a functional group. In the $\underline{4}$ electrode, a $\mathrm{C}$ $\mathrm{N}$ peak at $285.2 \mathrm{eV}$ corresponding to the amine group was also observed. After electrochemical polymerization of the thiopheneethanol, a characteristic C-O peak at $286.5 \mathrm{eV}$ due to a hydroxy group and C-S peaks were also observed. From these results, we confirmed that the conjugated phenylene polymer-modified ITO glass electrode could be successfully prepared by electrochemical polymerization onto an ITO glass electrode.

The cross-section SEM images of the conjugated phenylene polymer-modified ITO electrodes prepared by electrochemical polymerization are displayed in Figure 8. In the 1 electrode, the morphology of the conjugated phenylene polymer was a fiber structure, and the thickness of the conjugated phenylene polymer was $723 \mathrm{~nm}$. It is considered that the electron could be expected to transfer to an ITO glass electrode. The morphology and the thickness of the conjugated phenylene polymer were dense and $364 \mathrm{~nm}$, respectively, in the $\underline{\mathbf{2}}$ electrode. In the $\underline{\mathbf{3}}$ electrodes, the morphology of the conjugated phenylene polymer was a similar pattern to that of the $\underline{2}$ electrode and the thickness was $225 \mathrm{~nm}$. Thicknesses of these magnitudes for conjugated polymers are expected to be effective for electron transfer to ITO glass electrodes. In the $\underline{4}$ electrode, the morphology of the conjugated polymers was a rigid fiber structure that looked like a polyaniline structure, and the thickness of the conjugated polymer was $75.5 \mu \mathrm{m}$. It is considered that a conjugated phenylene polymer layer of such thickness would not be effective for electron transfer. In the $\underline{\mathbf{5}}$ electrode, the morphology appeared dense and the thickness was $235 \mathrm{~nm}$. These results strongly indicate that the conjugated phenylene polymer-modified ITO electrodes were successfully prepared by electrochemical polymerization.
TABLE 1: Band gap of the conjugated phenylene polymer-modified ITO electrodes determined by UV spectroscopy ${ }^{1}$.

\begin{tabular}{lc}
\hline Electron carriers & Band gap $(\mathrm{eV})$ \\
\hline$\underline{\mathbf{1}}$ & 3.91 \\
$\underline{\mathbf{2}}$ & 3.73 \\
$\underline{\mathbf{3}}$ & 2.90 \\
$\underline{\mathbf{4}}$ & 3.90 \\
$\underline{\mathbf{5}}$ & 3.95 \\
\hline
\end{tabular}

${ }^{1}$ Band gap $(\mathrm{eV})=1240 / x(2.24 \mathrm{eV})$.

The electrochemical impedance spectra of the conjugated phenylene polymer-modified ITO electrodes on a frequency range of $10^{-2} \sim 10^{4} \mathrm{~Hz}$ with an amplitude of $10 \mathrm{mV}$ in $0.1 \mathrm{MPBS}$ buffer ( $\mathrm{pH}=7.0$ ) containing $1.0 \mathrm{mM} \mathrm{K}_{3} \mathrm{Fe}(\mathrm{CN})_{6} / \mathrm{K}_{4} \mathrm{Fe}(\mathrm{CN})_{6}$ are shown in Figure 9. The Ret value of the bare ITO was observed at about $130 \Omega$; however, a relatively small Ret of $59 \Omega$ was observed in the $\mathbf{2}$ electrode, which indicates that it is an excellent conductor because of acceleration of electron transfer. The Ret values of the $\underline{\mathbf{1}}, \underline{\mathbf{3}}$, and $\underline{\mathbf{5}}$ electrodes were about $114 \Omega, 165 \Omega$, and $142 \Omega$, respectively, and the extremely large Ret value of the $\underline{4}$ electrode was obtained because of the thickness of the conjugated phenylene polymer or presence of a mixture of polymers (see structure in Figure 5). From these results, it was concluded that the conjugated phenylene polymer-modified ITO glass electrode is suitable for use as a photoanode in a solar cell.

In order to determine the band gap of the conjugated phenylene polymer, we analyzed the conjugated phenylene polymers prepared by electrochemical polymerization in accordance with the above described equation (5), and the band gap was between $2.90 \mathrm{eV}$ and $3.95 \mathrm{eV}$ (Table 1). From these results, it was concluded that the prepared conjugated phenylene polymer-modified ITO glass electrode is suitable for use as a photoanode in a solar cell.

Changes in the contact angles (Figure 10) of the bare ITO electrode (top) after electrochemical polymerization (middle) and immobilization of CdSe QDs (bottom) were examined. The contact angle of the bare ITO electrode surfaces was shown as $77.7^{\circ}$, while the contact angle values for the conjugated phenylene polymer-modified ITO electrodes $\underline{\mathbf{1}}, \underline{\mathbf{2}}, \underline{\mathbf{3}}, \underline{\mathbf{4}}$, and $\underline{\mathbf{5}}$ were $55.5^{\circ}, 50.6^{\circ}, 48.3^{\circ}, 58.3^{\circ}$, and $85.7^{\circ}$, respectively. The contact angles after electrochemical polymerization show a dramatic decrease of about $20^{\circ} \sim 30^{\circ}$ compared with that of the bare ITO electrode because of the hydrophilic properties of the conjugated phenylene polymers with functional group, except for the contact angle of the surface of the $\underline{5}$ electrode, which was increased because of the hydrophobic properties of the grafted thiophene polymers.

After immobilization of L-cys-capped CdSe QDs on the surface of the conjugated phenylene polymer-modified ITO electrodes, the contact angle values for the conjugated phenylene polymer-modified photoanodes $\underline{\mathbf{1}}, \underline{\mathbf{2}}, \underline{\mathbf{3}}, \underline{\mathbf{4}}$, and $\underline{\mathbf{5}}$ showed significant decreases of $36.4^{\circ}, 44.1^{\circ}, 15.3^{\circ}, 44.7^{\circ}$, and $22.2^{\circ}$, respectively. From these results, it was concluded that the conjugated phenylene polymer-modified photoanodes were successfully prepared by immobilization of L-cys-capped 

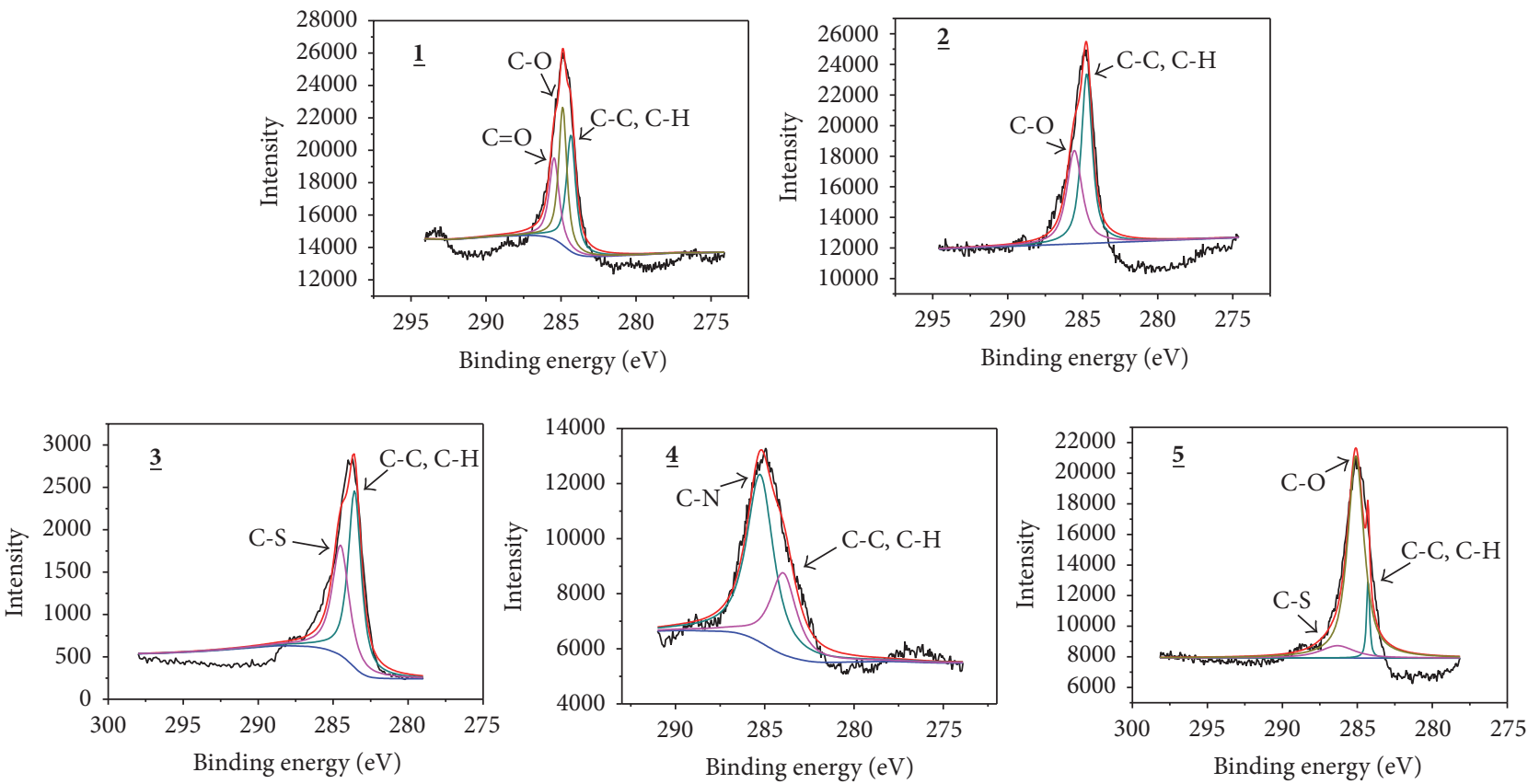

FIGURE 7: XPS spectra of the C 1s on the conjugated phenylene polymer-modified ITO electrodes.

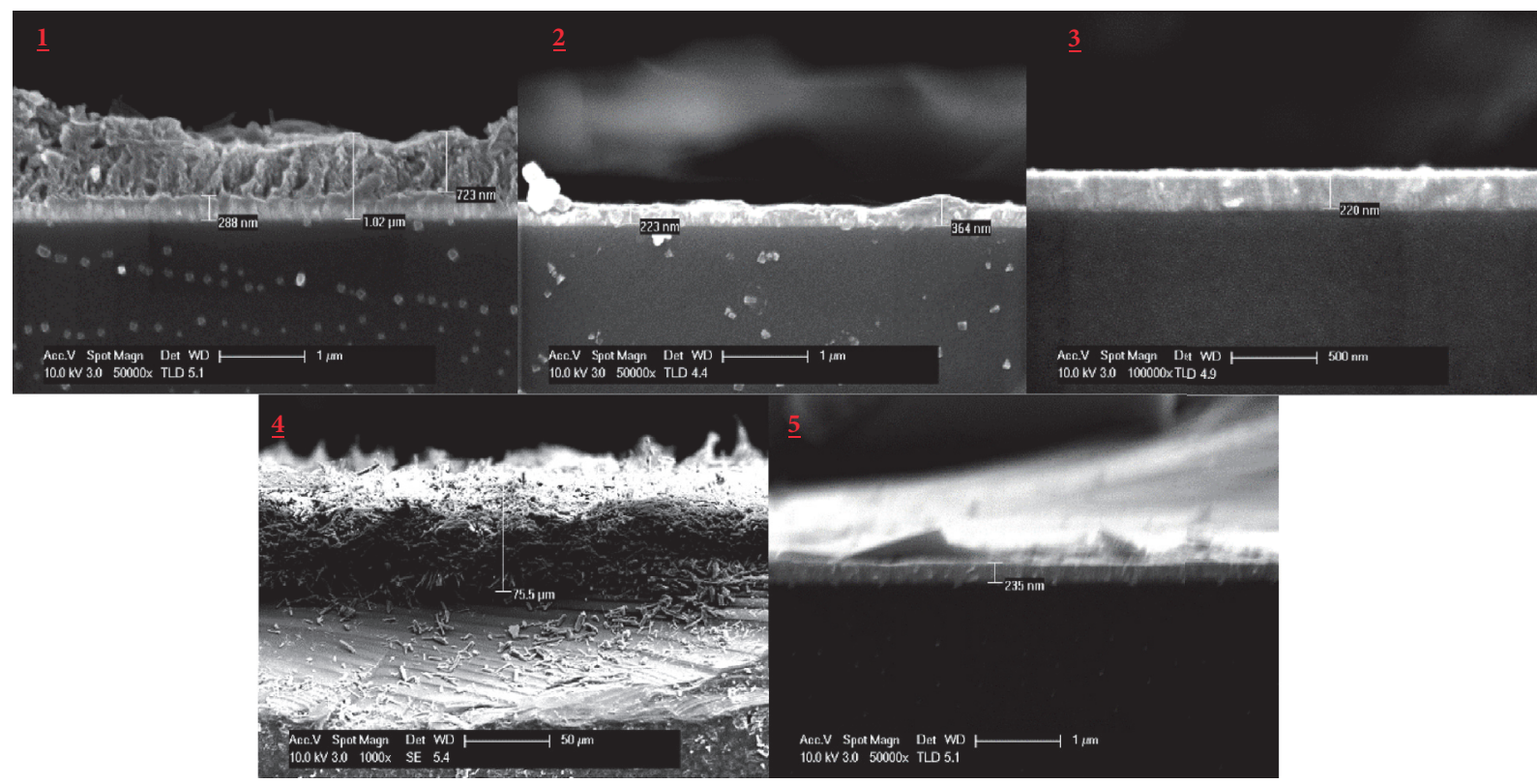

FIGURE 8: Cross-section SEM images of the conjugated phenylene polymer-modified ITO electrodes.

CdSe QDs onto the surface of the conjugated phenylene polymer-modified ITO electrodes.

In order to confirm the successful introduction of CdSe QDs on the photoanode, we carried out an analysis by highresolution XPS spectroscopy and obtained high-resolution XPS spectra of the Se 3d and Cd 3d of the conjugated phenylene polymer-modified photoanodes (Figures 11(a) and 11(b)). The Se $3 \mathrm{~d}$ peak at $55 \mathrm{eV}, \mathrm{Cd} 3 \mathrm{~d} 5 / 2$ peak at $404 \mathrm{eV}$, and $\mathrm{Cd} 3 \mathrm{~d} 3 / 2$ peak at $411 \mathrm{eV}$ appeared for all of the prepared conjugated phenylene polymer-modified photoanodes. From these results, we confirmed that the conjugated phenylene polymer-modified photoanodes were successfully prepared by immobilization of QDs after electrochemical polymerization.

For confirmation of CdSe QDs on the surface of the conjugated phenylene polymer-modified photoanodes, we observed the morphology of the prepared photoanodes (Figure 12). The surface morphology of the conjugated phenylene polymer-modified photoanode was an amorphous-like structure. Element mapping showed that the $\mathrm{Cd}$ and $\mathrm{Se}$ 

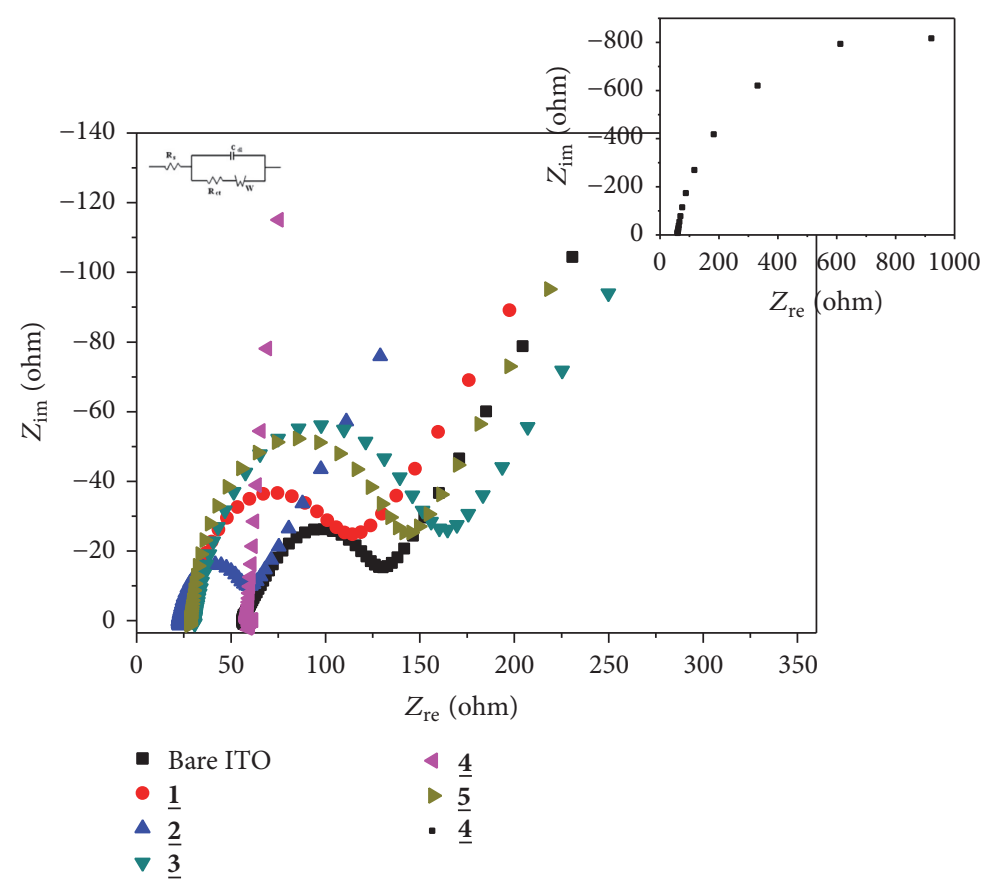

FIGURE 9: Electrochemical impedance spectra of the conjugated phenylene polymer-modified ITO electrodes on the frequency range of $10^{-2} \sim 10^{4} \mathrm{~Hz}$ with the amplitude of $10 \mathrm{mV}$ in $0.1 \mathrm{M}$ PBS buffer $(\mathrm{pH}=7.0)$ containing $1.0 \mathrm{mM} \mathrm{K}_{3} \mathrm{Fe}(\mathrm{CN})_{6} / \mathrm{K}_{4} \mathrm{Fe}(\mathrm{CN})_{6}$.

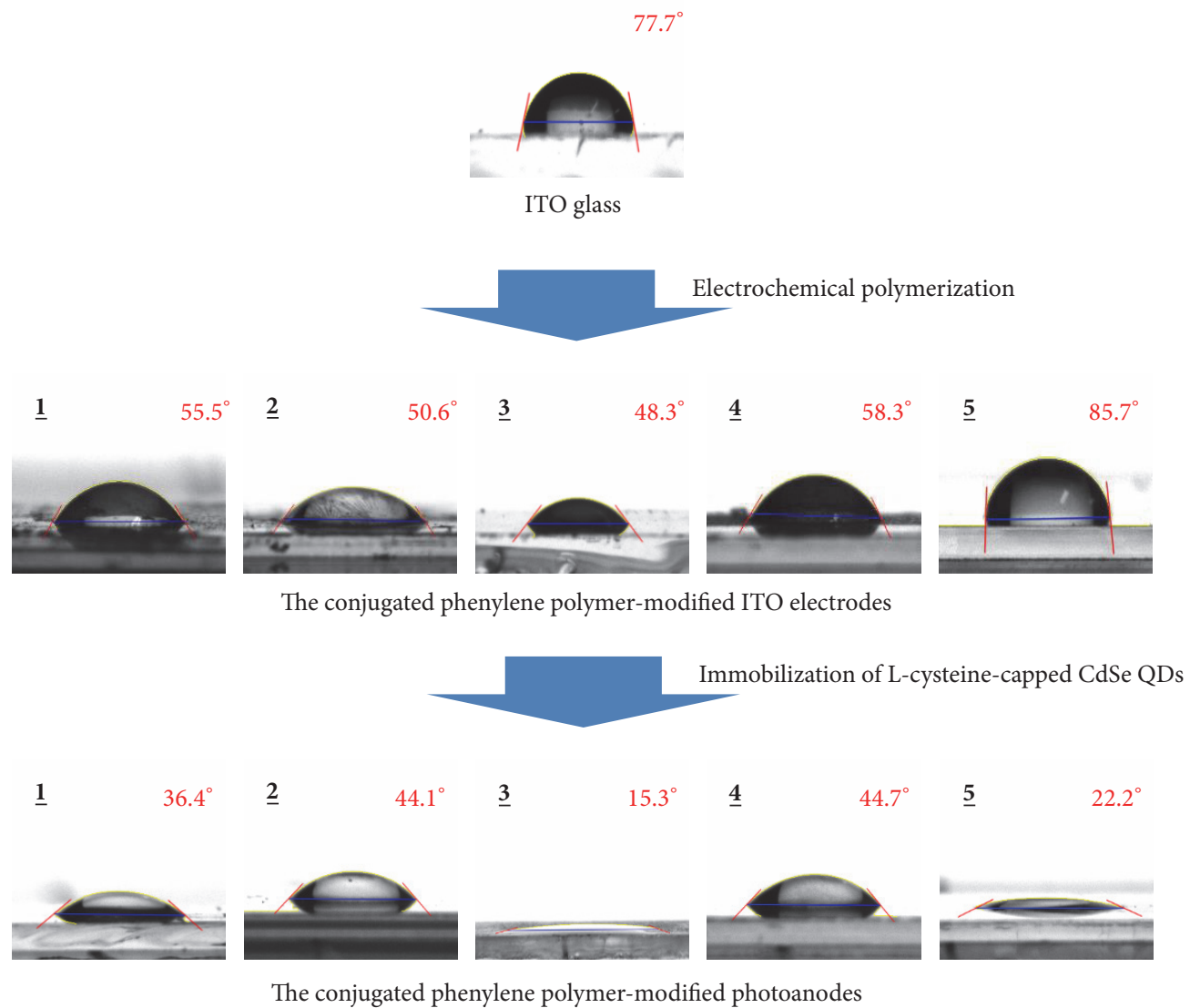

FIGURE 10: Contact angels of the bare ITO, the conjugated phenylene polymer-modified ITO electrodes, and photoanodes. 

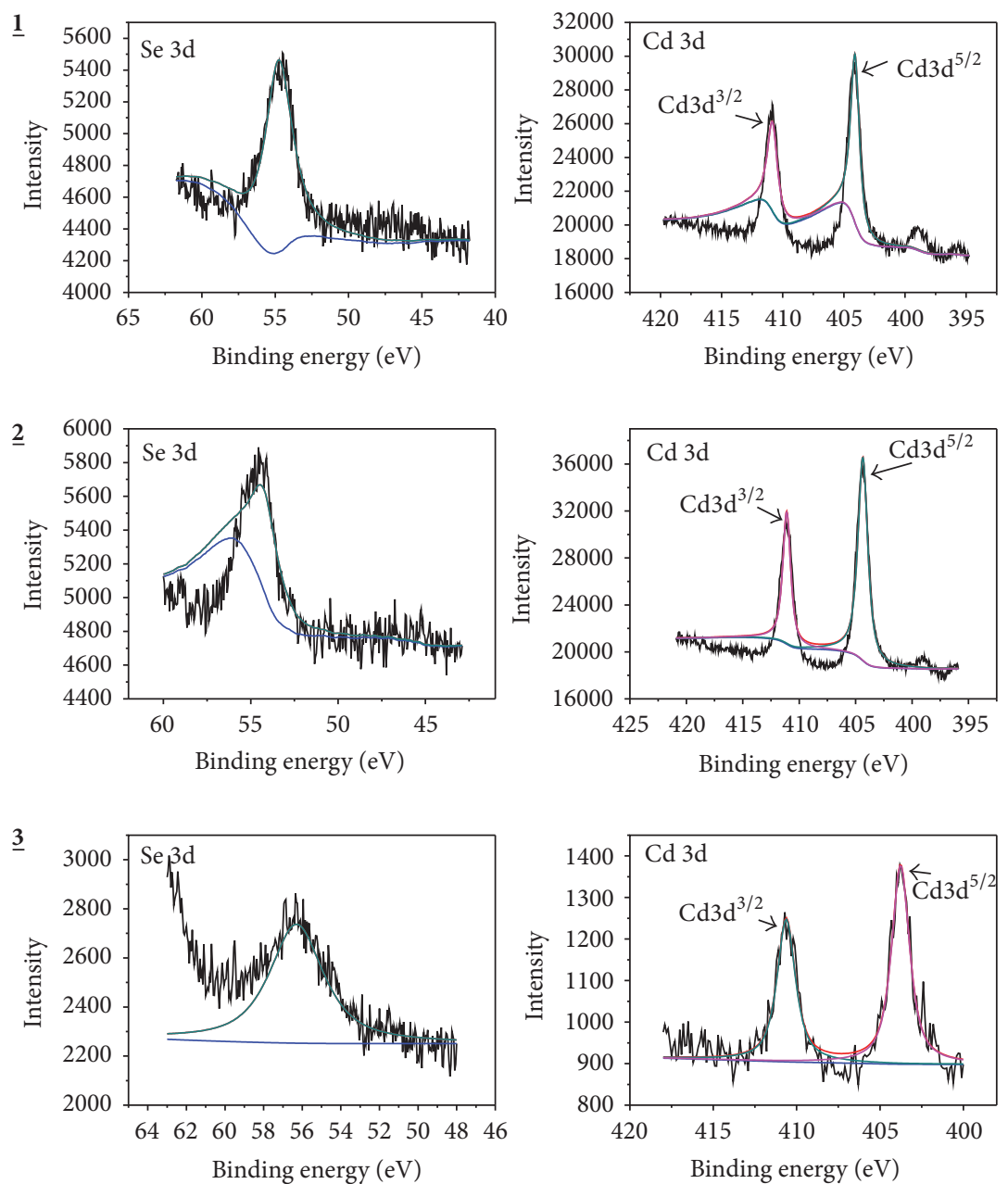

(a)
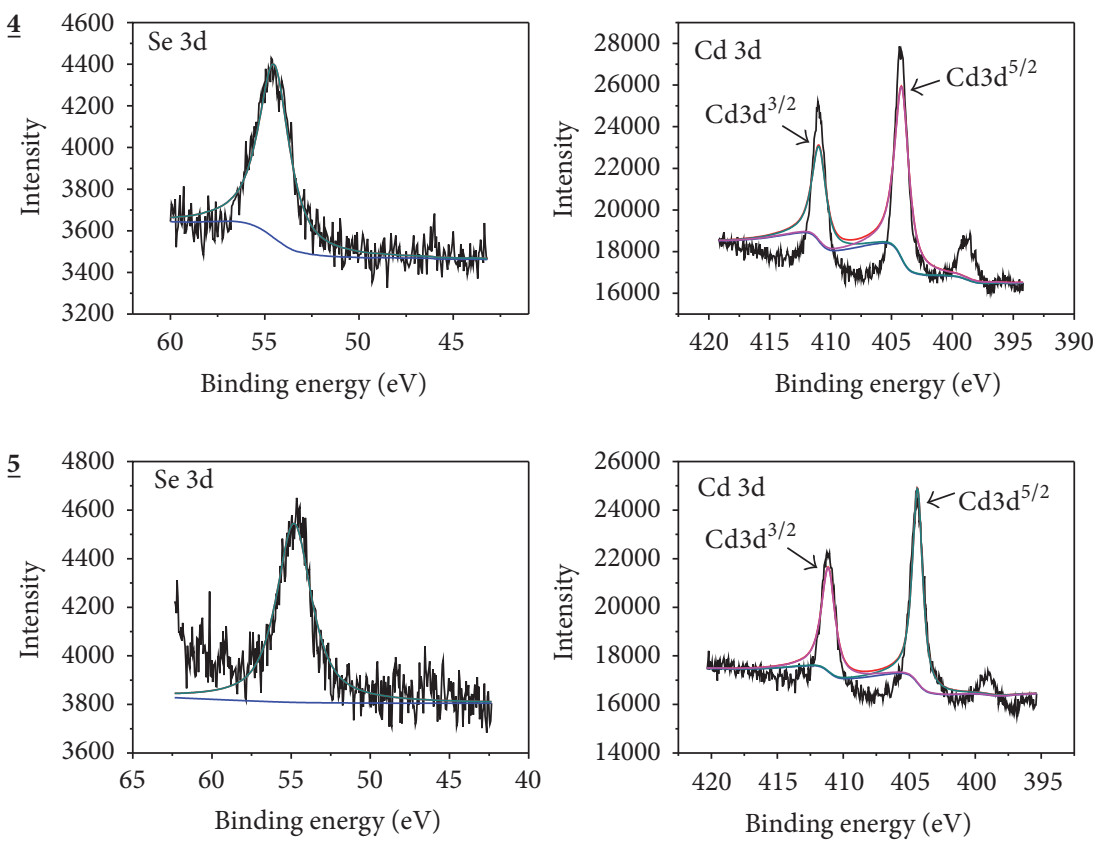

(b)

FIGURE 11: (a) XPS spectra of the Se 3d on the conjugated phenylene polymer-modified ITO electrodes. (b) XPS spectra of the Se 3d and the $\mathrm{Cd} 3 \mathrm{~d}$ on the conjugated phenylene polymer-modified ITO electrodes. 

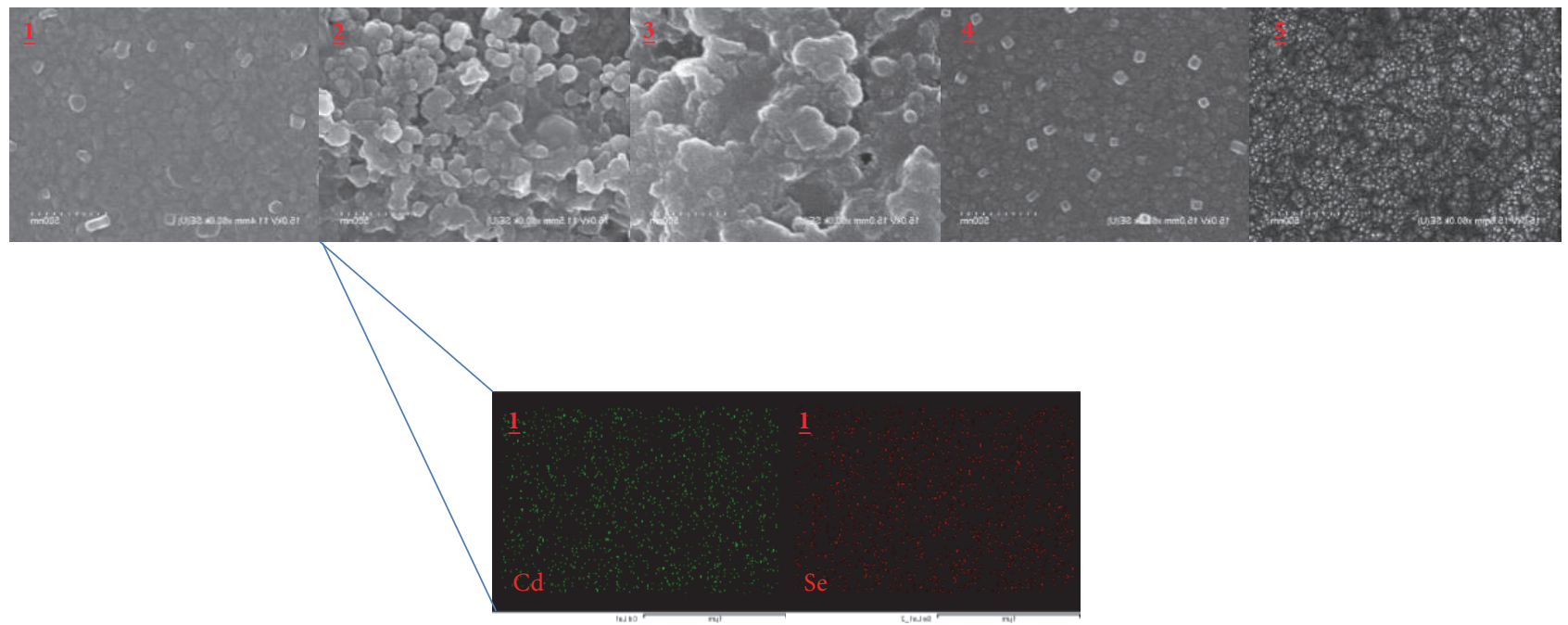

FIGURE 12: SEM images of the conjugated phenylene polymer-modified ITO electrodes. Elemental mapping of Cd and Se to $\underline{\mathbf{1}}$ photoanodes.

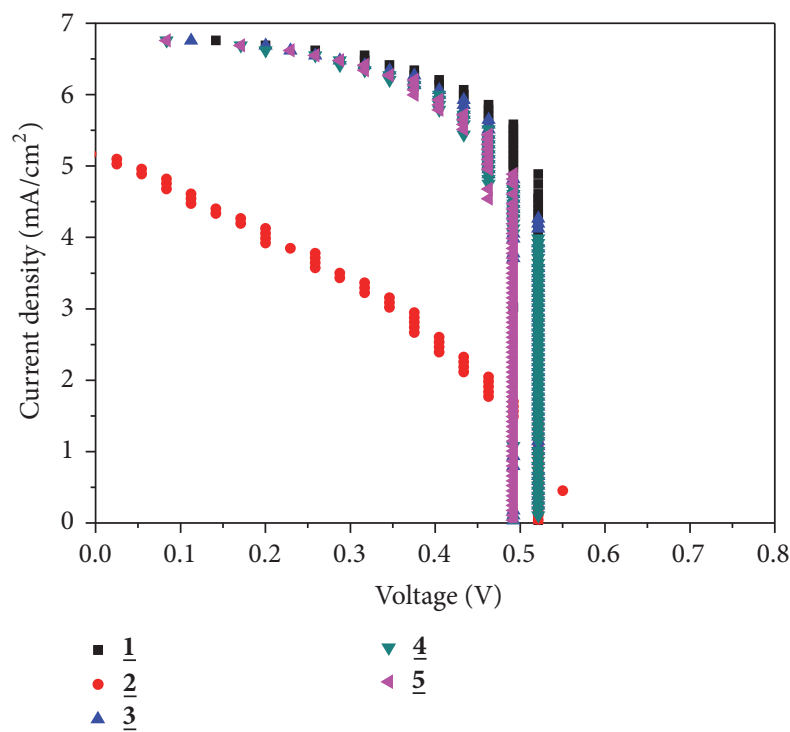

FIGURE 13: $J-V$ curves of the QDSSCs prepared by the conjugated phenylene polymer-modified ITO electrodes.

elements were dramatically dispersed onto the surface of the conjugated phenylene polymer-modified photoanodes. From the SEM results, we confirmed the successful preparation of the conjugated phenylene polymer-modified photoanodes by immobilization of the CdSe QDs after electrochemical polymerization.

Evaluation of QDSSCs prepared by the conjugated phenylene polymer-modified photoanodes $J-V$ curves of the QDSSCs prepared by the conjugated phenylene polymermodified photoanodes (Figure 13) clearly demonstrates that the deposition of the various electron transfer carrier modified CdSe thin layers significantly improved the cell performance. Power conversion efficiency $(\eta)$, fill factor (FF), open-circuit voltage $\left(V_{\mathrm{oc}}\right)$, and short circuit current $\left(J_{\mathrm{sc}}\right)$ to
TABLE 2: Power conversion efficiency $(\eta)$, fill factor (FF), open circuit voltage $\left(V_{\mathrm{oc}}\right)$, and short circuit current $\left(J_{\mathrm{sc}}\right)$ to QDSSCs prepared by photoanodes.

\begin{tabular}{lcccc}
\hline QDSSCs & $V_{\text {oc }}(\mathrm{V})$ & $J_{\text {sc }}\left(\mathrm{mA} \mathrm{cm}^{-2}\right)$ & FF $(\%)$ & $\eta(\%)$ \\
\hline$\underline{\mathbf{1}}$ & 0.52 & 6.83 & 76.8 & 2.73 \\
$\underline{\mathbf{2}}$ & 0.49 & 6.81 & 77.5 & 2.60 \\
$\underline{\mathbf{3}}$ & 0.49 & 6.79 & 75.8 & 2.54 \\
$\underline{\mathbf{4}}$ & 0.52 & 5.16 & 41.7 & 1.12 \\
$\underline{\mathbf{5}}$ & 0.49 & 6.81 & 74.7 & 2.50 \\
\hline
\end{tabular}

the QDSSCs prepared by photoanodes are shown in Table 2. Under one sun illumination (AM $1.5 \mathrm{G}, 100 \mathrm{~mW} \mathrm{~cm}^{-2}$ ), the maximum conversion efficiency $(\eta)$ of the cell was between 2.50 and $2.73 \%$ except for QDSSCs prepared by the $\underline{4}$ photoanode. Efficiency improved because of the prevention of recombination between the photoanode and the quantum dot sensitizer. As shown by these results, the conjugated phenylene-modified photoanodes were effective photoanodes in QDSSCs.

\section{Conclusions}

In this study, conjugated phenylene polymer-modified photoanodes for QDSSCs were prepared by immobilization of L-cys-capped QDs after electrochemical polymerization, and the prepared photoanodes were characterized. The size of the L-cysteine-capped CdSe QDs prepared by an aqueous solution method was below $5 \mathrm{~nm}$ and they were well dispersed. The preparation mechanism of the conjugated phenylene polymer-modified ITO electrodes was determined via cyclic voltammetry, FT-IR, XPS, SEM, contact angle, and impedance analysis. The maximum conversion efficiency $(\eta)$ of the cell was between 2.50 and $2.73 \%$ except for QDSSCs prepared by the $\underline{4}$ photoanode (see the structure in Figure 5). The conjugated phenylene-modified photoanodes were effective photoanodes in QDSSCs. 


\section{Competing Interests}

The authors declare that they have no competing interests.

\section{Acknowledgments}

This work was supported by the National Research Foundation of Korea grant, funded by the Korean Government (NRF-2015N043) and Hannam University Research Fund (2016).

\section{References}

[1] X. Yin, W. Que, D. Fei, H. Xie, and Z. He, "Effect of $\mathrm{TiO}_{2}$ shell layer prepared by wet-chemical method on the photovoltaic performance of $\mathrm{ZnO}$ nanowires arrays-based quantum dot sensitized solar cells," Electrochimica Acta, vol. 99, pp. 204-210, 2013.

[2] L. Li, X. Yang, W. Zhang, H. Zhang, and X. Li, "Boron and sulfur co-doped $\mathrm{TiO} 2$ nanofilm as effective photoanode for high efficiency CdS quantum-dot-sensitized solar cells," Journal of Power Sources, vol. 272, pp. 508-512, 2014.

[3] X. Shen, J. Jia, Y. Lin, and X. Zhou, "Enhanced performance of CdTe quantum dot sensitized solar cell via anion exchanges," Journal of Power Sources, vol. 277, pp. 215-221, 2015.

[4] A. J. Haring, M. E. Pomatto, M. R. Thornton, and A. J. Morris, " $\mathrm{Mn}{ }^{I I / I I I}$ complexes as promising redox mediators in quantumdot-sensitized solar cells," ACS Applied Materials and Interfaces, vol. 6, no. 17, pp. 15061-15067, 2014.

[5] P. Sehgal and A. K. Narula, "Quantum dot sensitized solar cell based on poly (3-hexyl thiophene)/CdSe nanocomposites," Optical Materials, vol. 48, pp. 44-50, 2015.

[6] S.-K. Kim, S. Park, M.-K. Son, and H.-J. Kim, "Ammonia treated $\mathrm{ZnO}$ nanoflowers based $\mathrm{CdS} / \mathrm{CdSe}$ quantum dot sensitized solar cell," Electrochimica Acta, vol. 151, pp. 531-536, 2015.

[7] J. Qi, W. Liu, C. Biswas et al., "Enhanced power conversion efficiency of CdS quantum dot sensitized solar cells with $\mathrm{ZnO}$ nanowire arrays as the photoanodes," Optics Communications, vol. 349, pp. 198-202, 2015.

[8] Q. Shen, T. Sato, M. Hashimoto, C. Chen, and T. Toyoda, "Photoacoustic and photoelectrochemical characterization of CdSe-sensitized $\mathrm{TiO} 2$ electrodes composed of nanotubes and nanowires," Thin Solid Films, vol. 499, no. 1-2, pp. 299-305, 2006.

[9] K. S. Leschkies, R. Divakar, J. Basu et al., "Photosensitization of $\mathrm{ZnO}$ nanowires with CdSe quantum dots for photovoltaic devices," Nano Letters, vol. 7, no. 6, pp. 1793-1798, 2007.

[10] X. Song, M. Wang, J. Deng et al., " ZnO/PbS core/shell nanorod arrays as efficient counter electrode for quantum dot-sensitized solar cells," Journal of Power Sources, vol. 269, pp. 661-670, 2014.

[11] J. Li, S. K. Cushing, P. Zheng et al., "Solar hydrogen generation by a CdS- $\mathrm{Au}-\mathrm{TiO}_{2}$ sandwich nanorod array enhanced with au nanoparticle as electron relay and plasmonic photosensitizer," Journal of the American Chemical Society, vol. 136, no. 23, pp. 8438-8449, 2014.

[12] C.-Z. Yao, B.-H. Wei, L.-X. Meng et al., "Controllable electrochemical synthesis and photovoltaic performance of $\mathrm{ZnO} / \mathrm{CdS}$ core-shell nanorod arrays on fluorine-doped tin oxide," Journal of Power Sources, vol. 207, pp. 222-228, 2012.

[13] J. Chen, C. Li, J. L. Song, X. W. Sun, W. Lei, and W. Q. Deng, "Bilayer $\mathrm{ZnO}$ nanostructure fabricated by chemical bath and its application in quantum dot sensitized solar cell," Applied Surface Science, vol. 255, no. 17, pp. 7508-7511, 2009.
[14] Y. Lai, Z. Lin, D. Zheng, L. Chi, R. Du, and C. Lin, "CdSe/CdS quantum dots co-sensitized $\mathrm{TiO} 2$ nanotube array photoelectrode for highly efficient solar cells," Electrochimica Acta, vol. 79, pp. 175-181, 2012.

[15] J. Zhang, C. Tang, and J. H. Bang, "CdS/TiO $2-\mathrm{SrTiO}_{3}$ heterostructure nanotube arrays for improved solar energy conversion efficiency," Electrochemistry Communications, vol. 12, no. 8, pp. 1124-1128, 2010.

[16] Z. Li, L. Yu, Y. Liu, and S. Sun, "CdS/CdSe quantum dots Cosensitized $\mathrm{TiO}_{2}$ Nanowire/Nanotube solar cells with enhanced efficiency," Electrochimica Acta, vol. 129, pp. 379-388, 2014.

[17] D.-J. Chung, S.-H. Oh, S. Komathi, A. I. Gopalan, K. P. Lee, and S.-H. Choi, "One-step modification of various electrode surfaces using diazonium salt compounds and the application of this technology to electrochemical DNA (E-DNA) sensors," Electrochimica Acta, vol. 76, pp. 394-403, 2012.

[18] S.-R. Lee, H.-E. Lee, Y. O. Kang, W.-S. Hwang, and S.-H. Choi, "Bienzymatic Acetylcholinesterase and Choline oxidase immobilized biosensor based on a phenyl carboxylic acid-grafted multiwalled carbon nanotube," Advances in Materials Science and Engineering, vol. 2014, Article ID 971942, 12 pages, 2014.

[19] H.-E. Lee, Y. O. Kang, and S.-H. Choi, "Electrochemical-DNA biosensor development based on a modified carbon electrode with gold nanoparticles for influenza a (H1N1) detection: effect of spacer," International Journal of Electrochemical Science, vol. 9, no. 12, pp. 6793-6808, 2014.

[20] J.-S. Park, Y. O. Kang, S.-R. Lee, H. Bae, S. Choi, and S.-H. Choi, "Fabrication of an electrogenerated chemiluminescence biosensor based on CdSe quantum dots for the determination of Acetylcholine," Sensor Letters, vol. 13, no. 1, pp. 85-91, 2015.

[21] D.-W. Deng, J.-S. Yu, and Y. Pan, "Water-soluble CdSe and CdSe/CdS nanocrystals: a greener synthetic route," Journal of Colloid and Interface Science, vol. 299, no. 1, pp. 225-232, 2006. 

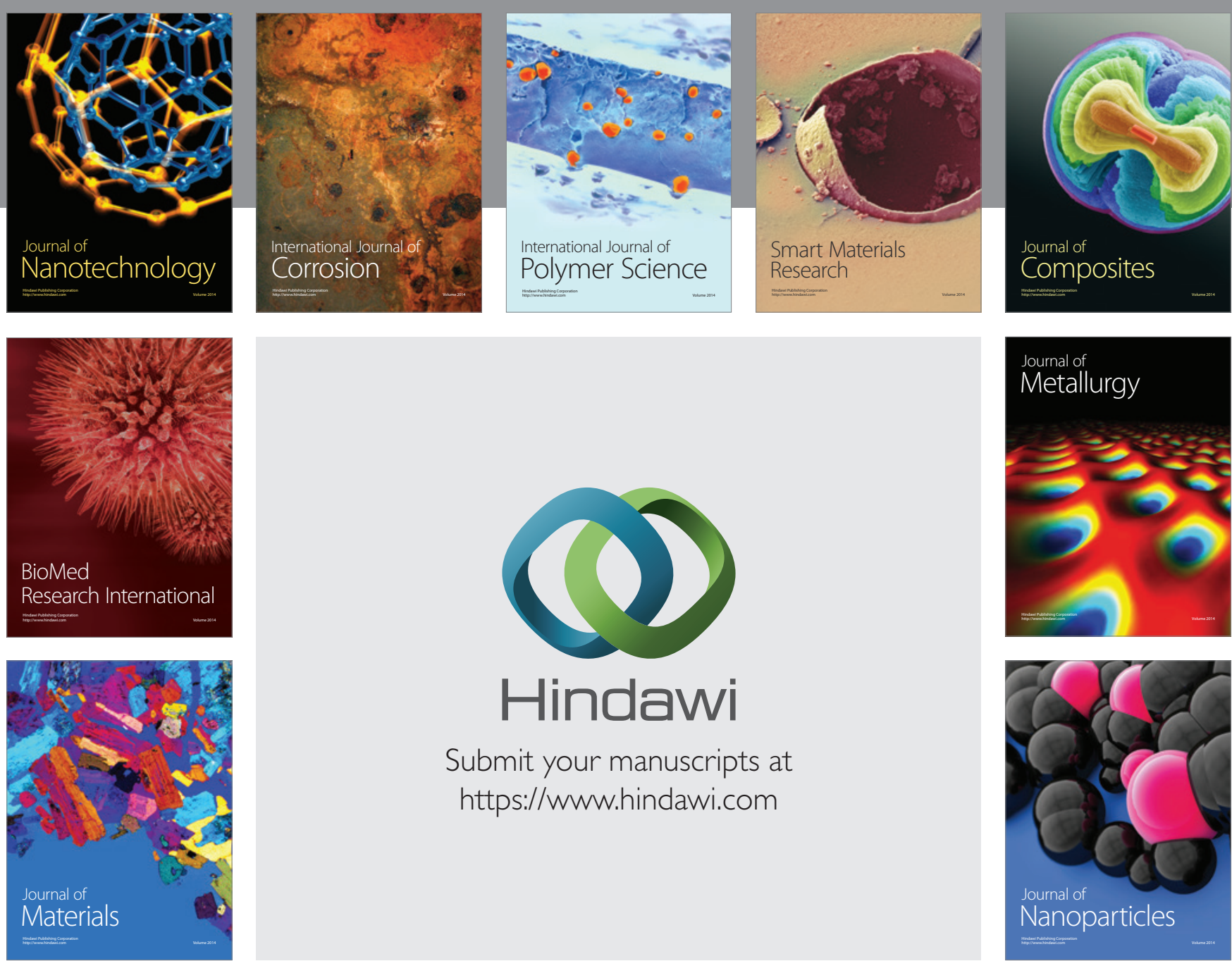

\section{Hindawi}

Submit your manuscripts at

https://www.hindawi.com

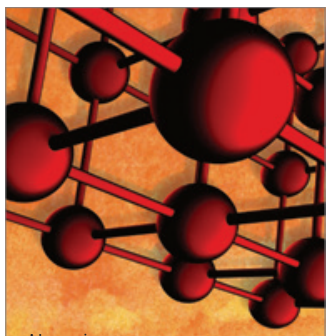

Materials Science and Engineering
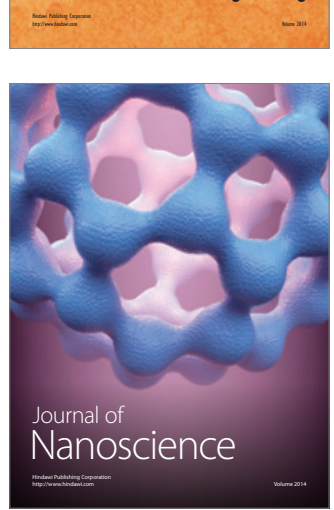
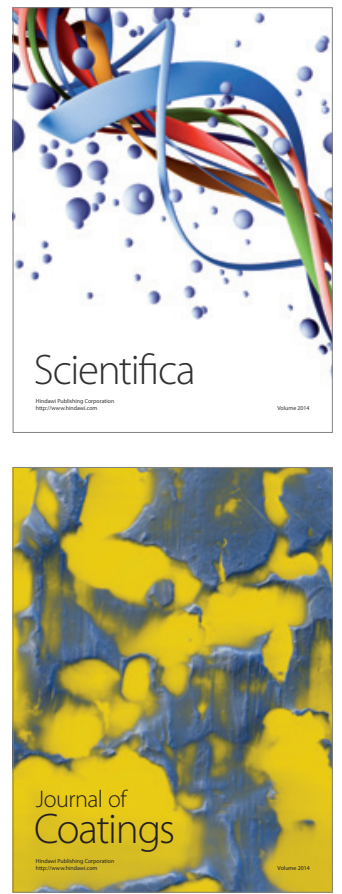
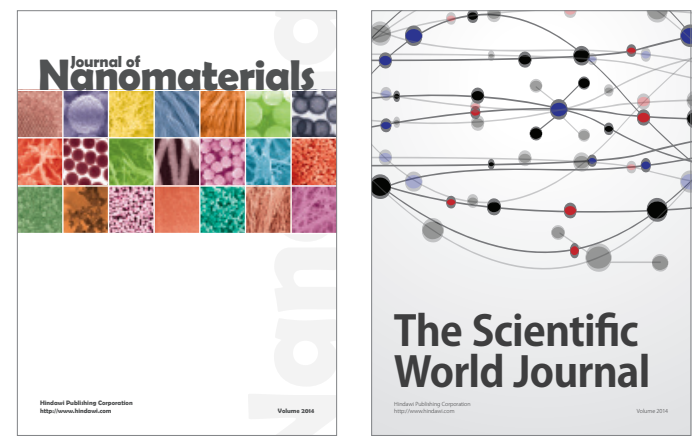

The Scientific World Journal
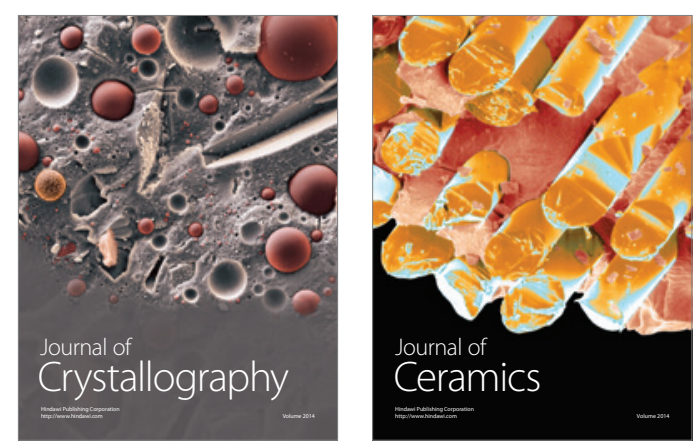
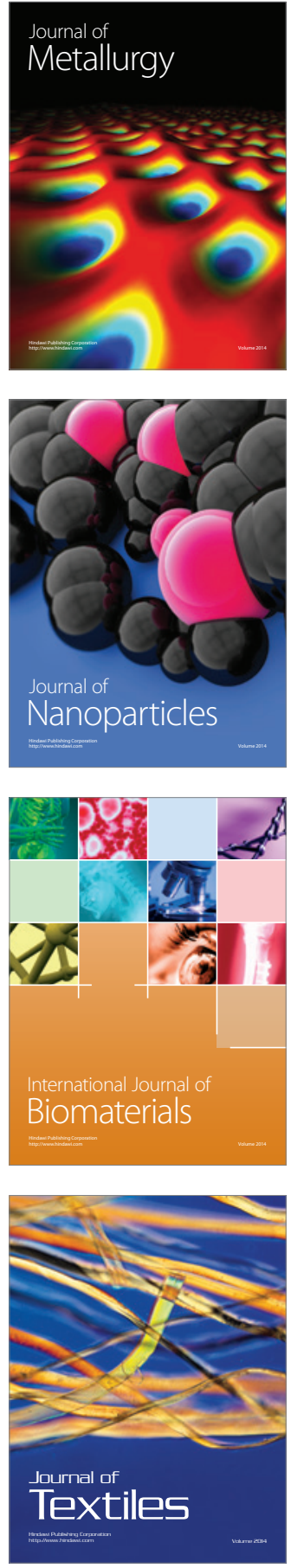